\title{
ATTENUATION OF HAEMODYNAMIC RESPONSE TO LARYNGOSCOPY \& INTUBATION- A COMPARATIVE STUDY BETWEEN ORAL GABAPENTIN AND ORAL CLONIDINE
}

\author{
Arunima Saikia1, Raju Prasad Tayung², Maumita Saha ${ }^{3}$ \\ ${ }_{1}^{1}$ Associate Professor, Department of Anaesthesiology, Assam Medial College, Dibrugarh, Assam, India. \\ ${ }^{2}$ Assistant Professor, Department of Anaesthesiology, Assam Medial College, Dibrugarh, Assam, India. \\ ${ }_{3}^{3}$ Medical and Health Officer, Department of Anaesthesiology, Assam Medial College, Dibrugarh, Assam, India.
}

\section{ABSTRACT}

\section{BACKGROUND}

Laryngoscopy and endotracheal intubation are very essential tools in the hands of an anaesthesiologist in securing \& maintaining the air way \& administration of general anaesthesia. Direct laryngoscopy and endotracheal intubation are noxious stimuli that can lead to adverse response of cardiovascular, respiratory and other systems. Reid and Bruce, in the year 1904 \& King Harris in 1951 described the circulatory response following laryngoscopy \& tracheal intubation due to the stimulation of larynx and trachea as reflex sympatho-adrenal system.1,2

\section{METHODS}

150 normotensive adult consenting patients aged 20-15 years, ASA grade 1 and grade 2 of both genders, were randomized into two treatment groups of 75 patients each. Group A patients received tablet of Gabapentin $900 \mathrm{mg}$ and group B patients received tablet of Clonidine 200 micrograms, 120 minutes before surgery. 150 patients were randomly divided into two equal groups of 75 each namely group A and group B. Anaesthetic technique was standardized and all groups were assessed for haemodynamic changes before administration of study drug ( $\mathrm{t} 1$ ), just before taking the patients in OT ( $\mathrm{t} 2$ ), before intubation ( $\mathrm{t} 3$ ), after intubation ( $\mathrm{t} 4)$, 0 minutes, 3 minutes, 5 minutes, 10 minutes, 30 minutes after intubation.

\section{RESULTS}

Significantly decreased heart rate, systolic blood pressure, diastolic blood pressure, mean arterial blood pressure and pulse pressure product were observed in both group A and group B, after laryngoscopy and intubation.

\section{CONCLUSIONS}

Gabapentin $900 \mathrm{mg}$ attenuates the pressure response due to laryngoscopy and intubation better than Clonidine 200 mg. However, the attenuation of heart rate in both groups is similar.

\section{KEY WORDS}

Laryngoscopy, Endotracheal Intubation, Oral Gabapentin, Oral Clonidine

HOW TO CITE THIS ARTICLE: Saikia A, Tayung RP, Saha M. Attenuation of haemodynamic response to laryngoscopy \& intubationa comparative study between oral gabapentin and oral clonidine. J. Evolution Med. Dent. Sci. 2019;8(26):2119-2125, DOI: $10.14260 /$ jemds/2019/466

\section{BACKGROUND}

The laryngoscopy and endotracheal intubation are very essential and important tools in the hands of anaesthesiologist in securing and maintaining the airway and administering general anaesthesia.

Direct laryngoscopy and endotracheal intubation are noxious stimuli that can lead to adverse response to cardiovascular, respiratory and other physiological responses. Reid and Bruce, in the year 1940 and King Harris in 1951 described about the circulatory response following laryngoscopy and tracheal intubation due to the stimulation of larynx and trachea as reflex sympathoadrenal system.1,2

Although increase in heart rate and blood pressure due to the sympathoadrenal response are short lived, they may have detrimental and adverse effects in high risk patients, like

'Financial or Other Competing Interest': None.

Submission 11-05-2019, Peer Review 18-06-2019,

Acceptance 24-06-2019, Published 01-07-2019.

Corresponding Author:

Dr. Raju Prasad Tayung,

Assistant Professor

Department of Anaesthesiology,

Assam Medial College, Dibrugarh, Assam, India.

E-mail: drrtayung14@gmail.com

DOI: $10.14260 /$ jemds $/ 2019 / 466$

\section{(c) (i) $\$$}

those with cardiovascular disease, vascular anomalies or intratracheal disease. This hemodynamic response due to laryngoscopy and intubation is the result of an increase in the levels of circulatory catecholamines which cause the elevation of blood pressure and heart rate. ${ }^{3,4,5}$ Gabapentin is a GABA analogue, which was originally introduced as an antiepileptic. Later it was proved to be effective in reducing neuropathic as well as post-operative pain. During the studies, it was observed that gabapentin attenuates the preoperative anxiety and stress response to intubation. ${ }^{6}$

Clonidine is an $\alpha 2$ agonist is an antihypertensive agent which acts centrally to reduce the sympathetic outflow. Clonidine premedication, thus, produces sedation and blunts the stress response to laryngoscopy and intubation. ${ }^{7}$

The present study is undertaken to determine the efficacy of oral gabapentin $900 \mathrm{mg}$ and oral clonidine $200 \mathrm{mcg}$ in attenuating the sympathetic response to laryngoscopy and tracheal intubation and to compare the effect of oral gabapentin and oral clonidine in attenuating hemodynamic response to laryngoscopy and intubation.

\section{METHODS}

Study Design

Prospective clinical study. 
After obtaining an approval of research and ethics committee of hospital and after having written and informed consent from each patient, 150 adult patients scheduled for elective open cholecystectomy surgery under General Anaesthesia in Assam Medical College and Hospital, Dibrugarh were selected randomly by matching the parameters and were provided general anaesthesia with endotracheal intubation for all the patients.

\section{Inclusion Criteria}

- $\quad$ Patients aged between 20-50 years of both the sexes.

- $\quad$ Patients with ASA Grade I and Group II.

- Patients undergoing elective open cholecystectomy surgery under General anaesthesia.

\section{Exclusion Criteria}

- Unwilling Patients.

- Emergency Surgeries.

- Patients with ASA Grade III or higher.

- Patients with Neurological and other endocrine abnormalities.

- Patients with renal impairment and hepatic disease.

- Patients with congestive heart failure, Valvular heart disease, Hypertension, Diabetes Mellitus, IHD.

- Patients on Psychotropic drugs or history of drug allergies.

- Difficult intubation.

- Previous records of failed intubation.

150 patients were randomly divided into two equal groups of 75 each namely group A and group B.

Group "A" patient received tablet of Gabapentin 900 mg and

Group "B" patient received tablet of Clonidine 200 microgram

The drug was given to each patient of group A and group B, 120 minutes before the operation.

\section{Statistics}

All data were analysed by specific statistical methods applicable to various sets of data. Tests employed are unpaired $t$ test, paired $t$ test, Fischer's and chi-square test using the computer programme Graph pad, and Microsoft word and Excel sheet. Microsoft word and excel have been used to generate graphs, tables etc.

\section{Methods of Data Collection}

Patients heart rate, systolic blood pressure, diastolic blood pressure, mean blood pressure, SPO2, were monitored before the administration of study drug ( $\mathrm{t} 1$ ), just before taking the patients in OT ( $\mathrm{t} 2)$, before intubation ( $\mathrm{t} 3$ ), after intubation (t4) $0 \mathrm{~min}, 3 \mathrm{~min}, 5 \mathrm{~min}, 10 \mathrm{~min}, 30 \mathrm{~min}$ after intubation.

\section{RESULTS}

\begin{tabular}{|c|c|c|c|c|c|}
\hline \multirow{2}{*}{ Time } & \multicolumn{2}{|c|}{ Gabapentin } & \multicolumn{2}{|c|}{ Clonidine } & \multirow{2}{*}{ p Value } \\
\hline & Mean & SD & Mean & SD & \\
\hline $\begin{array}{c}\mathrm{t}_{1} \text { (before drug } \\
\text { administration) }\end{array}$ & 84.5067 & \pm 9.23913 & 88.3467 & \pm 15.1751 & 0.0632 \\
\hline $\begin{array}{l}\mathrm{t}_{2} \text { (before taking } \\
\text { the patient to OT) }\end{array}$ & 84.88 & \pm 14.8924 & 87.6 & \pm 14.1994 & 0.2541 \\
\hline $\begin{array}{c}\mathrm{t}_{3} \text { (before } \\
\text { intubation) }\end{array}$ & 84.8533 & \pm 11.1291 & 87.3733 & \pm 14.0143 & 0.2246 \\
\hline $\begin{array}{c}\mathrm{t}_{4}(\text { After } \\
\text { intubation) } 0 \mathrm{~min}\end{array}$ & 100.093 & \pm 11.9844 & 101.267 & \pm 12.3664 & 0.558 \\
\hline
\end{tabular}

\begin{tabular}{|c|c|c|c|c|c|}
\hline $3 \mathrm{~min}$ & 91.1467 & \pm 11.1667 & 94.2 & \pm 11.0869 & 0.095 \\
\hline $5 \mathrm{~min}$ & 85.52 & \pm 9.3899 & 88.1867 & \pm 8.86489 & 0.0758 \\
\hline $10 \mathrm{~min}$ & 86.3467 & \pm 11.2868 & 89.9067 & \pm 14.4336 & 0.0946 \\
\hline $30 \mathrm{~min}$ & 85.6933 & \pm 10.6933 & 88.2267 & \pm 12.0377 & 0.1641 \\
\hline At extubation & 102.28 & \pm 9.04278 & 104.627 & \pm 12.1974 & 0.1827 \\
\hline \multicolumn{6}{|c|}{ Table 1. Intergroup Comparison of Heart Rate } \\
\hline
\end{tabular}

\begin{tabular}{|c|c|c|c|c|c|}
\hline \multirow{2}{*}{ Time } & \multicolumn{2}{|c|}{ Gabapentin } & \multicolumn{2}{c|}{ Clonidine } & \multirow{2}{*}{ p Value } \\
\cline { 2 - 5 } & Mean & SD & Mean & SD & \\
\hline $\begin{array}{c}\text { t } 1 \text { (before drug } \\
\text { administration) }\end{array}$ & 129.28 & \pm 8.52748 & 130.4 & \pm 12.5354 & $0.5233 ; \mathrm{NS}$ \\
\hline $\begin{array}{c}\mathrm{t}_{2} \text { (before taking } \\
\text { the patient to } \\
\text { OT) }\end{array}$ & 128.293 & \pm 15.6609 & 129 & \pm 11.1598 & $0.7506 ; \mathrm{NS}$ \\
\hline $\begin{array}{c}\mathrm{t}_{3} \text { (before } \\
\text { intubation) }\end{array}$ & 128.093 & \pm 9.72066 & 130.08 & \pm 10.6286 & $0.0 .2341 ; \mathrm{NS}$ \\
\hline $\begin{array}{c}\mathrm{t}_{4} \text { (After } \\
\text { intubation) } \\
\text { min }\end{array}$ & 142.173 & \pm 9.25228 & 147.333 & \pm 9.64692 & $0.0218 ; \mathrm{S}$ \\
\hline 3 min & 132.787 & \pm 8.03757 & 136.587 & \pm 8.29375 & $0.0050 ; \mathrm{HS}$ \\
\hline 5 min & 129.64 & \pm 8.30441 & 133.013 & \pm 8.23882 & $0.0136 ; \mathrm{S}$ \\
\hline 10 min & 128.88 & \pm 7.80152 & 131.773 & \pm 9.20572 & 0.0396 \\
\hline 30 min & 128.867 & \pm 7.05449 & 131.547 & \pm 8.70274 & $0.04 ; \mathrm{S}$ \\
\hline At extubation & 145.013 & \pm 6.14574 & 147.773 & \pm 7.86469 & $0.0179 ; \mathrm{S}$ \\
\hline \multicolumn{7}{|c|}{ Table 2. Intergroup Comparison of SBP } & \\
\hline
\end{tabular}

\begin{tabular}{|c|c|c|c|c|c|}
\hline \multirow{2}{*}{ Time } & \multicolumn{2}{|c|}{ Gabapentin } & \multicolumn{2}{c|}{ Clonidine } & \multirow{2}{*}{ p Value } \\
\cline { 2 - 5 } & Mean & SD & Mean & SD & \\
\hline $\begin{array}{c}\mathrm{t}_{1} \text { (before drug } \\
\text { administration) }\end{array}$ & 79.3067 & \pm 6.41572 & 78.84 & \pm 6.77244 & $0.6655 ; \mathrm{NS}$ \\
\hline $\begin{array}{c}\mathrm{t}_{2} \text { (before } \\
\text { taking the } \\
\text { patient to 0T) }\end{array}$ & 80.7733 & \pm 10.5556 & 78.4533 & \pm 6.86017 & $0.1126 ; \mathrm{NS}$ \\
\hline $\begin{array}{c}\mathrm{t}_{3} \text { (before } \\
\text { intubation) }\end{array}$ & 80.8 & \pm 7.17 & 80.65 & \pm 7.3 & $0.8991 ; \mathrm{NS}$ \\
\hline $\begin{array}{c}\mathrm{t}_{4} \text { ( After } \\
\text { intubation) } \\
0 \text { min }\end{array}$ & 93.4533 & \pm 8.57604 & 96.6 & \pm 8.03876 & $0.0218 ; \mathrm{S}$ \\
\hline 3 min & 85.1733 & \pm 8.12799 & 87.7867 & \pm 5.71223 & $0.0241 ; \mathrm{S}$ \\
\hline 5 min & 81.28 & \pm 7.88354 & 84.04 & \pm 5.6552 & $0.0149 ; \mathrm{S}$ \\
\hline 10 min & 78.16 & \pm 6.93608 & 80.667 & \pm 7.06788 & $0.0299 ; \mathrm{S}$ \\
\hline 30 min & 80.133 & \pm 6.6322 & 82.5733 & \pm 7.96135 & $0.0432 ; \mathrm{S}$ \\
\hline At extubation & 94.3467 & \pm 6.38726 & 96.8133 & \pm 5.66567 & $0.0134 ; \mathrm{S}$ \\
\hline \multicolumn{7}{|c|}{ Table 3. Intergroup Comparison of DBP } & \\
\hline
\end{tabular}

\begin{tabular}{|c|c|c|c|c|c|}
\hline \multirow{2}{*}{ Time } & \multicolumn{2}{|c|}{ Gabapentin } & \multicolumn{2}{c|}{ Clonidine } & \multirow{2}{*}{ p Value } \\
\cline { 2 - 5 } & Mean & SD & Mean & SD & \\
\hline $\begin{array}{c}\mathrm{t}_{1} \text { (before drug } \\
\text { administration) }\end{array}$ & 95.9644 & \pm 5.26179 & 96.0267 & \pm 6.88641 & $0.9504 ; \mathrm{NS}$ \\
\hline $\begin{array}{c}\mathrm{t}_{2} \text { (before taking } \\
\text { the patient to } \\
\text { OT) }\end{array}$ & 96.6133 & \pm 11.1357 & 95.3022 & \pm 6.46617 & $0.3793 ; \mathrm{NS}$ \\
\hline $\begin{array}{c}\mathrm{t}_{3} \text { (before } \\
\text { intubation) }\end{array}$ & 96.56 & \pm 6.618 & 97.1288 & \pm 6.8986 & $0.6071 ; \mathrm{NS}$ \\
\hline $\begin{array}{c}\mathrm{t}_{4} \text { (After } \\
\text { intubation)0 } \\
\text { min }\end{array}$ & 109.693 & \pm 7.62104 & 113.511 & \pm 7.26697 & $0.002 ; \mathrm{HS}$ \\
\hline 3 min & 101.044 & \pm 7.13982 & 104.053 & \pm 5.02577 & $0.0033 ; \mathrm{HS}$ \\
\hline 5 min & 97.4 & \pm 6.59443 & 100.364 & \pm 5.06865 & $0.0024 ; \mathrm{HS}$ \\
\hline 10 min & 95.0667 & \pm 5.95756 & 97.7022 & \pm 6.20364 & $0.0088 ; \mathrm{HS}$ \\
\hline 30 min & 96.2978 & \pm 5.88671 & 98.8978 & \pm 6.34067 & $0.0102 ; \mathrm{S}$ \\
\hline At extubation & 111.236 & \pm 5.10866 & 113.8 & \pm 5.2827 & $0.0030 ; \mathrm{S}$ \\
\hline \multicolumn{7}{|c|}{ Table 4. Intergroup Comparison of MAP } & \\
\hline
\end{tabular}

\begin{tabular}{|c|c|c|c|c|c|}
\hline \multirow{2}{*}{ Time } & \multicolumn{2}{|c|}{ Gabapentin } & \multicolumn{2}{c|}{ Clonidine } & \multirow{2}{*}{ p Value } \\
\cline { 2 - 5 } & Mean & SD & Mean & SD & p \\
\hline $\begin{array}{c}\mathrm{t}_{1} \text { (before drug } \\
\text { administration) }\end{array}$ & 10939.9 & \pm 1509.33 & 11573.9 & \pm 2565.94 & $0.0671 ; \mathrm{NS}$ \\
\hline $\begin{array}{c}\mathrm{t}_{2} \text { (before taking } \\
\text { the patient to 0T) }\end{array}$ & 10962.4 & \pm 2726.87 & 11350.6 & \pm 2343.18 & $0.3513 ; \mathrm{NS}$ \\
\hline $\begin{array}{c}\mathrm{t}_{3} \text { (before } \\
\text { intubation) }\end{array}$ & 10903.6 & \pm 1896.73 & 11407.4 & \pm 2285.83 & $0.1440 ; \mathrm{NS}$ \\
\hline $\begin{array}{c}\mathrm{t}_{4} \text { (After } \\
\text { intubation)0 min }\end{array}$ & 14241.6 & \pm 2037.43 & 14936.6 & \pm 2207.4 & $0.0467 ; \mathrm{S}$ \\
\hline 3 min & 12122.3 & \pm 1796.9 & 12877.9 & \pm 1802.07 & $0.0111 ; \mathrm{S}$ \\
\hline
\end{tabular}




\begin{tabular}{|c|c|c|c|c|c|}
\hline $5 \mathrm{~min}$ & 11109 & \pm 1586.42 & 11738.5 & \pm 1455.93 & $0.0124 ; \mathrm{S}$ \\
\hline $10 \mathrm{~min}$ & 11145.3 & \pm 1739.23 & 11870.4 & \pm 2227.82 & $0.0278 ; \mathrm{S}$ \\
\hline $30 \mathrm{~min}$ & 11057.9 & \pm 1564.82 & 11633.7 & \pm 1925.67 & $0.0463 ; \mathrm{S}$ \\
\hline At extubation & 14839.2 & \pm 1538.69 & 15474.7 & \pm 2085.79 & $0.0354 ; \mathrm{S}$ \\
\hline \multicolumn{7}{|c|}{ Table 5. Intergroup Comparison of PPP } \\
\hline
\end{tabular}

\begin{tabular}{|c|c|c|c|c|}
\hline Side Effects & Clonidine & $\mathbf{\%}$ & Gabapentin & $\%$ \\
\hline Bradycardia(HR<60 bpm) & 8 & $10.67 \%$ & - & - \\
\hline Hypotension & - & - & - & - \\
\hline Preinduction dryness of mouth & 7 & $9.33 \%$ & - & - \\
\hline Post-operative drowsiness & - & - & 12 & $16 \%$ \\
\hline Preoperative dizziness & - & - & - & - \\
\hline \multicolumn{6}{|l|}{ Table 6. Incidence of Side Effects } \\
\hline
\end{tabular}
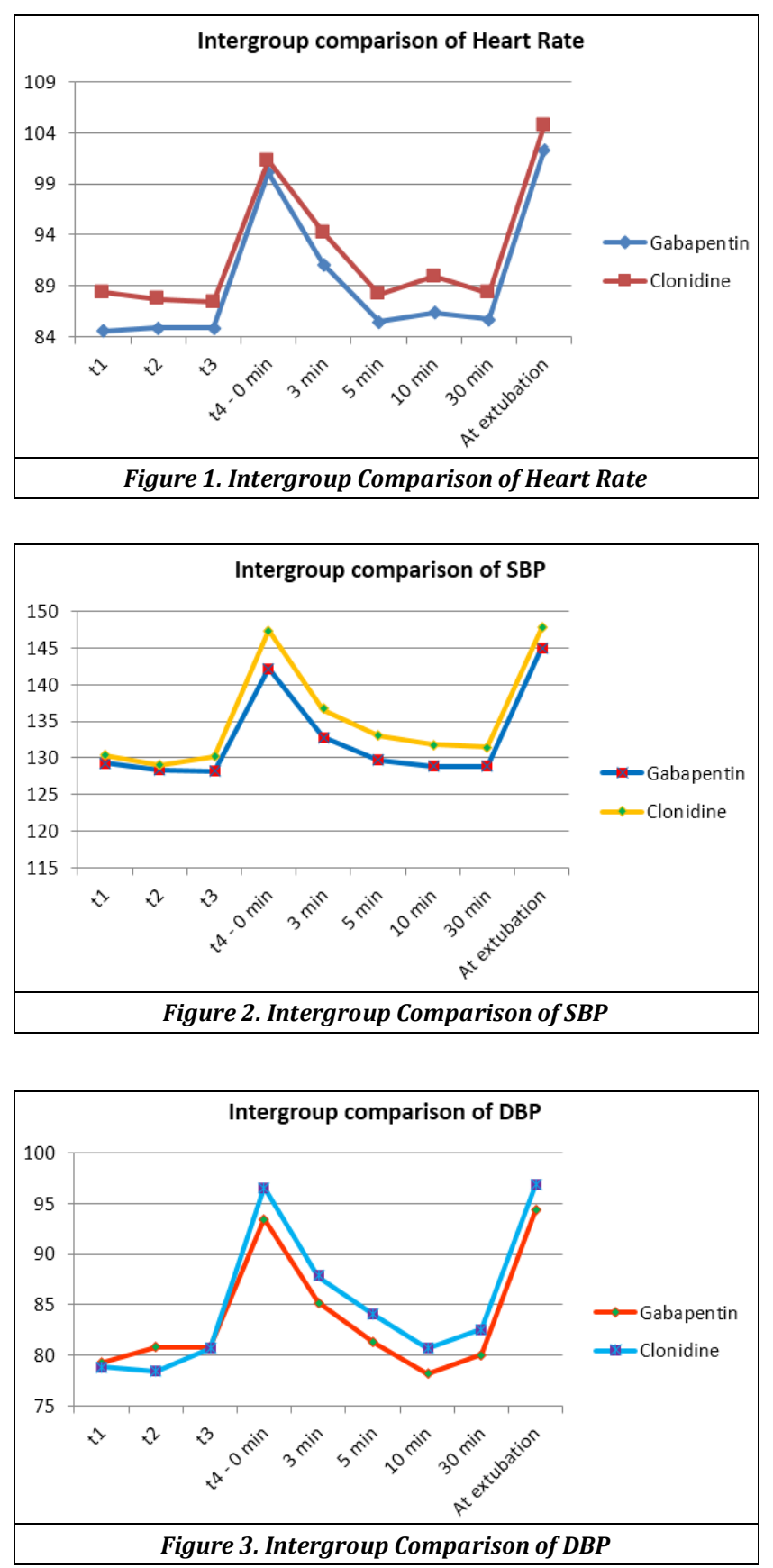
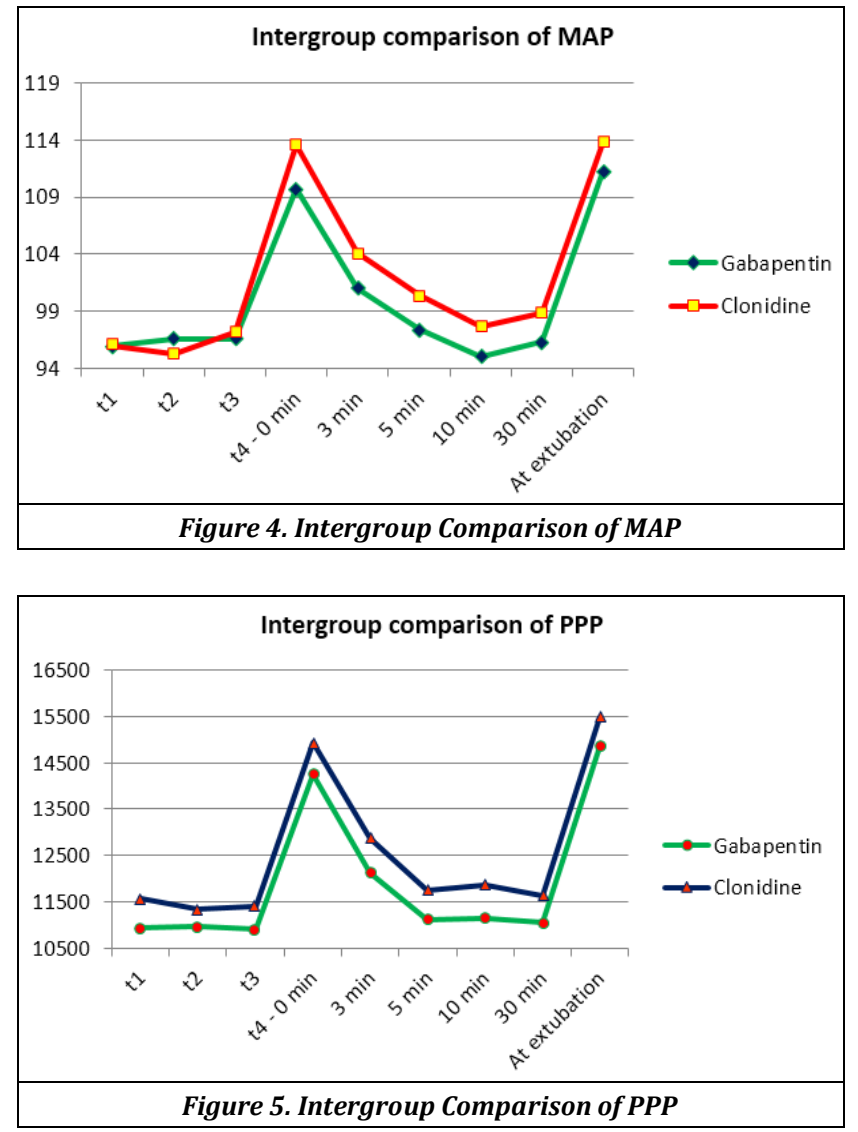

At the end of the surgery, reversal was done with inj. Neostigmine $0.05 \mathrm{mg} / \mathrm{kg}$ and inj. Glycopyrrolate $0.01 \mathrm{mg} / \mathrm{kg}$ i.v after being evaluated for adequate reversal. Extubation was done after reversal of the non-depolarizing muscle relaxant.

Post-extubation heart rate, systolic blood pressure, diastolic blood pressure, mean blood pressure, SPO2 were noted.

Grades of sedation using Modified Ramsay sedation score and analgesia by using Visual analogue scale was evaluated.

Lastly the dose of inducing agent was also compared.

An observation was made related to adverse effects of drugs and anaesthesia related problems and was attended to appropriately.

General anaesthesia in Assam medical college and hospital, Dibrugarh were selected by matching the parameters and were provided general anaesthesia with endotracheal intubation for all the patients.

150 patients were randomly divided into two equal groups of 75 each namely group A and group B.

Group "A" patient received tablet of Gabapentin $900 \mathrm{mg}$ and

Group "B" patient received tablet of Clonidine 200 microgram

The drug was given to each patient of group A and group $\mathrm{B}, 120$ minutes before the operation.

In intergroup comparison, it is found that, there is no significant difference between the heart rates in both the groups at any point of time. ( $p$ value $>0.05$ ).

The intergroup comparison of SBP of the study groups were done. There were no significant difference between the baselines SBP among the two groups. The SBP just before taking the patient to $\mathrm{OT}$ and before intubation was similar in both the groups and there were no significant difference. ( $p$ 
value $>0.05$ ). After intubation the mean SBP increased in both the groups. However in the gabapentin group it was significantly lower than the Clonidine group ( $p$ value $<0.05$ ) at $0 \mathrm{~min}, 3 \mathrm{~min}, 5 \mathrm{~min}, 10 \mathrm{~min}$ and $30 \mathrm{~min}$ after intubation. Even after extubation the SBP in the gabapentin group was significantly less than the Clonidine group.

In the intergroup comparison of DBP it is seen that the baseline DBP was similar in both the groups and there was no significant difference between the two groups. The DBP just before taking the patient to OT and before intubation was slightly more in the gabapentin group, however the difference from Clonidine group was statistically insignificant. After intubation the DBP increased in both the groups but in the Clonidine group the rise of DBP at $0 \mathrm{~min}, 3 \mathrm{~min}, 5 \mathrm{~min}, 10 \mathrm{~min}$ and 30 min were more than the gabapentin group and the difference between the two was statistically significant. (p value<0.05). Again after extubation, the DBP in the Clonidine group was significantly more than the gabapentin group.

The intergroup comparison between the gabapentin and Clonidine groups were done and it was seen that the MAP before administration of the study drugs, before taking the patient to OT and before intubation were similar in both the groups, the difference being statistically insignificant. There was a rise of MAP in both Clonidine group and Gabapentin group after intubation but it was more in the Clonidine group. At $0 \mathrm{~min}, 3 \mathrm{~min}, 5 \mathrm{~min}$ and $10 \mathrm{~min}$ after intubation the difference between the MAP was statistically very significant. At 30 min after intubation and at extubation the difference was statistically significant and it was more in the Clonidine group. In the intergroup comparison of PPP it was seen that the PPP in both Gabapentin and Clonidine group before giving study drug, just before taking the patient to OT and before intubation were similar and the difference is statistically insignificant. After intubation the PPP increased in both the groups but it was more in the Clonidine group, the difference between two are statistically significant. Also after extubation it was more in the Clonidine group and there was significant difference from the Gabapentin group.

From the above table it can be deduced that incidence of side effects were reported in both the study groups. In the Clonidine group $10.67 \%$ of patients showed bradycardia whereas $9.33 \%$ patients complained of dryness of mouth in pre-induction period. In the Gabapentin group post-operative drowsiness was reported in $16 \%$ of patients.

\section{DISCUSSION}

Obtunding the hemodynamic response to stress, associated with anaesthesia and surgery is a major concern in the current practice of anaesthesia. Perioperative anxiety and stress of anaesthesia and surgery produce undesirable effects in the form of tachycardia and hypertension respectively.

Heart rate, systolic blood pressure, diastolic blood pressure, mean arterial pressure and the pulse pressure product were recorded and compared in both the groups. ECG, $\mathrm{SpO}_{2}$ and $\mathrm{EtCO}_{2}$ were also observed and recorded. Patients were also closely monitored for any side effects or complications. The hemodynamic parameters were recorded in fixed intervals-before giving the study drug $\left(t_{1}\right)$, before taking the patient to OT $\left(\mathrm{t}_{2}\right)$, before intubation $\left(\mathrm{t}_{3}\right)$. After intubation( $\left(\mathrm{t}_{4}\right)$ at $0 \mathrm{~min}, 3 \mathrm{~min}, 5 \mathrm{~min}, 10 \mathrm{~min}$ and $30 \mathrm{~min}$ and at extubation.

\section{Heart Rate}

The mean baseline heart rate ( $t_{1}$, before drug administration) is statistically insignificant in both gabapentin and clonidine group ( $\mathrm{p}$ value $>0.05$ ).

After the study drug was given the mean heart rate in gabapentin group and the Clonidine group were similar to the baseline and the change from baseline was not statistically significant. (p value $>0.05$. Before intubation, also, in both groups the change from baseline was not statistically significant.(p value >0.05). After laryngoscopy and intubation, heart rate increased in both the groups. In Gabapentin group there was $18.44 \%$ increase in heart rate from baseline which is statistically extremely significant. ( $p$ value $<0.0001$ ). Similarly, in Clonidine group the heart rate raised by $14.624 \%$ from the baseline and the change was extremely significant.(p value<0.0001)In both the groups heart rate came down to near baseline values 5 minute after intubation and remained so till 30 minute. Again, after extubation, the heart rate increased by $21.031 \%$ and 18.428 $\%$ in Gabapentin and Clonidine group respectively which was extremely significant ( $p$ value $>0.0001$ ). In the intergroup comparison, it was found that, there was no significant difference between the heart rates in both the groups at any point of time ( $\mathrm{p}$ value $>0.05$ ).

\section{Systolic Blood Pressure}

The intragroup comparison of SBP in the Gabapentin group and the Clonidine shows that, there is no significant change in the SBP from baseline, just before taking the patient to OT $\left(\mathrm{t}_{2}\right)$ and before intubation $\left(\mathrm{t}_{3}\right)$. However, after intubation the mean SBP at 0 min and $3 \mathrm{~min}$ increased significantly by $9.72 \%$ and $2.71 \%$ in the gabapentin group and $12.99 \%$ and $4.74 \%$ in the Clonidine group from the baseline. The SBP in both the groups came down to near baseline values at $10 \mathrm{~min}$ post intubation till $30 \mathrm{~min}$ and there is no significant difference between the SBP at these time periods from the baseline. Again there was a significant increase in SBP seen after extubation when there is $12.17 \%$ and $13.32 \%$ increase in the gabapentin and the Clonidine group was seen. In the intergroup comparison it was found that the SBP just before taking the patient to OT and before intubation were similar in both the groups and there were no significant difference.( $p$ value $>0.05$ ). After intubation the mean SBP increased in both the groups. However in the gabapentin group it was significantly lower than the Clonidine group ( $p$ value $<0.05$ ) at $0 \mathrm{~min}, 3 \mathrm{~min}, 5 \mathrm{~min}, 10 \mathrm{~min}$ and $30 \mathrm{~min}$ after intubation. Even after extubation the SBP in the Gabapentin group was significantly less ( $\mathrm{p}$ value $<0.05$ ) than the Clonidine group.

\section{Diastolic Blood Pressure}

The baseline DBP in both the groups were comparable. In both the groups it was seen that the DBP were comparable to baseline before taking the patient to OT $\left(\mathrm{t}_{2}\right)$ and before intubation $\left(t_{3}\right)$ and there were no significant difference from the baseline values. After intubation there was an increase of DBP by $17.84 \%$ and $7.4 \%$ from baseline at $0 \mathrm{~min}$ and $3 \mathrm{~min}$ in the Gabapentin group and $22.53 \%$ and $11.35 \%$ in the Clonidine group which is statistically extremely significant ( $p$ value $<0.0001$ ). However, in the Gabapentin group the DBP came down to near baseline values at $5 \mathrm{~min}$ till $30 \mathrm{~min}$ after intubation. But in the Clonidine group the DBP remain raised till 30 min after intubation and the difference from baseline 
were statistically significant. Again after extubation there was a rise of DBP by $18.96 \%$ in the gabapentin group and $22.8 \%$ in the Clonidine group from baseline was seen and the difference being extremely significant. ( $p$ value $<0.0001$ ).

In the intergroup comparison of DBP it is seen that the baseline DBP was similar in both the groups and there was no significant difference between the two groups. The DBP just before taking the patient to OT $\left(t_{2}\right)$ and before intubation $\left(t_{3}\right)$ was slightly more in the Gabapentin group, however the difference from Clonidine group was statistically insignificant. After intubation the DBP increased in both the groups but in the Clonidine group the rise of DBP at $0 \mathrm{~min}, 3$ min, $5 \mathrm{~min}, 10 \mathrm{~min}$ and $30 \mathrm{~min}$ were more than the Gabapentin group and the difference between the two was statistically significant. ( $p$ value $<0.05$ ). Again after extubation, the DBP in the Clonidine group was significantly more than the Gabapentin group.

\section{Mean Arterial Pressure}

Baseline mean MAP of the two groups were comparable. The MAP just before taking the patient to OT $\left(\mathrm{t}_{2}\right)$ and before intubation $\left(\mathrm{t}_{3}\right)$ in both the groups were comparable to the baseline and the difference from the baseline is statistically insignificant. After intubation the MAP in the Gabapentin group increased by $14.31 \%$ and $5.29 \%$ and in the Clonidine group by $18.21 \%$ and $8.36 \%$, at 0 min and 3 min respectively, the difference from baseline being statistically extremely significant. However the MAP came down to near baseline levels in the Gabapentin group at 5 min after intubation and remained so till $30 \mathrm{~min}$. The difference from the baseline MAP was not significant. But in the Clonidine group the MAP remain raised till 30 min after intubation and the difference from baseline was statistically significant( $p$ value $<0.05)$ Again there was a rise of MAP in both the groups after extubation was seen, the difference from baseline being extremely significant(p value <0.05). The intergroup comparison between the Gabapentin and Clonidine groups were done and it was seen that the MAP before administration of the study drugs, before taking the patient to OT and before intubation were similar in both the groups, the difference being statistically insignificant. There was a rise of MAP in both Clonidine group and Gabapentin group after intubation. At $0 \mathrm{~min}, 3 \mathrm{~min}, 5 \mathrm{~min}, 10 \mathrm{~min}$ and $30 \mathrm{~min}$ it was more in the Clonidine group when compared with the Gabapentin group and the difference between the MAP was statistically significant. Also at extubation the difference was statistically significant and it was more in the Clonidine group.

\section{Pulse Pressure Product}

Pulse pressure product also called as double pressure product is considered as an indirect measure of myocardial oxygen consumption. The lower the value a drug produces the better is cardio protective effect of a drug. The baseline PPP values were comparable in both the groups. The intragroup comparison of the Gabapentin group and the Clonidine group shows that the PPP just before taking the patient to OT and before intubation were comparable to the baseline. The difference from baseline are statistically insignificant. However there was a rise of PPP in both the groups after intubation at $0 \mathrm{~min}$ and $3 \mathrm{~min}$, the difference from baseline being statistically extremely significant. The
PPP came down to near baseline level at 5 min till $30 \mathrm{~min}$ after intubation in both the groups. Again it was raised, in both groups at extubation the difference from baseline being extremely significant.

In the intergroup comparison of PPP it was seen that the PPP in both Gabapentin and Clonidine group before giving study drug, just before taking the patient to OT and before intubation were similar and the difference is statistically insignificant. After intubation the PPP increased in both the groups but it was more in the Clonidine group, the difference between two are statistically significant. Also after extubation it was more in the Clonidine group and there was significant difference from the Gabapentin group.

\section{Dose Selection}

Both Gabapentin and Clonidine have been used in different doses in different studies for blunting the hemodynamic response to laryngoscopy and intubation. Gabapentin has been used in the dose range of 400-1600 mg in both single and multiple doses and Clonidine was used in the range of 100-300 mcg.

Following are some studies where these two drugs had been used in different doses for attenuating the hemodynamic response due to laryngoscopy and intubation.

Dr. Dipak L. Raval et al oral Clonidine pre medication for attenuation of haemodynamic response to laryngoscopy and intubation. They used Clonidine at a dose of $4 \mathrm{mcg} / \mathrm{kg}$ given 90 minutes prior to induction of anaesthesia. ${ }^{8}$

U. Bafna et $\mathrm{Al}$ conducted a study to evaluate the effectiveness of Gabapentin in attenuating the hemodynamic response to laryngoscopy and intubation. They compared two doses of Gabapentin $600 \mathrm{mg}$ and $1000 \mathrm{mg}$, in this placebo-controlled study. ${ }^{9}$

Sarita Sharma et al conducted a study to compare and evaluate the effect of Gabapentin, Clonidine and combination of both the drugs to attenuate the pressor response to direct laryngoscopy and intubation. Patients were given oral 800 mg of Gabapentin (Group A), $300 \mu \mathrm{g}$ of Clonidine (Group B), $400 \mathrm{mg}$ of Gabapentin and $150 \mu \mathrm{g}$ of Clonidine (Group C) and placebo (Group D) 60 minutes (min.) prior to induction of anaesthesia. 10

Dr. Mamatha. H. K et al conducted a comparative study between oral Clonidine at a dose of $4 \mathrm{mcg} / \mathrm{kg}$ and iv Clonidine at a dose of $3 \mathrm{mcg} / \mathrm{kg}$ to attenuate the hemodynamic response to laryngoscopy and intubation. ${ }^{11}$

In this study $900 \mathrm{mg}$ of gabapentin and $200 \mathrm{mcg}$ of Clonidine was chosen as many authors had chosen these doses to study these drugs.

Timing of the drug-Both Gabapentin and Clonidine has their peak action 1-2 hours after the oral administration. So, the study drug was given 2 hours before surgery.

Following are some studies where Gabapentin $900 \mathrm{mg}$ and Clonidine $200 \mathrm{mcg}$ had been used to study their effect in attenuating hemodynamic response to laryngoscopy and intubation:

Mansoor Soltanzadeh et al studied the effects of preoperative oral gabapentin in reduction of intraocular pressure and cardiovascular changes following laryngoscopy and tracheal intubation. In this placebo-controlled study 900 mg of gabapentin was given two hours before the surgery. ${ }^{12}$

Dr Joshi Vyankatesh S., et al conducted a study to evaluate the effectiveness of oral clonidine and lignocaine to attenuate 
the haemodynamic response due to laryngoscopy and intubation; and also, to compare these two drugs. In their study they used oral Clonidine at a dose of 200 mcg given 90 min prior to induction of anaesthesia. ${ }^{13}$

Suresh K. Singhal, Kiranpreet Kaur et al compared the effects of oral clonidine and gabapentin as premedicant in obtunding hemodynamic response to laryngoscopy and intubation in normotensive patients undergoing elective surgery. A total of 100 patients of either sex enrolled in the study were randomly divided into two groups of 50 each. Group A patients received oral clonidine $200 \mu$ g and Group B patients received oral gabapentin $900 \mathrm{mg}, 90 \mathrm{~min}$ prior to induction of anaesthesia. ${ }^{14}$

In the pre-laryngoscopy period, the baseline hemodynamic parameters i.e. before giving the study drug (t1) were comparable in both the groups and there was no significant difference ( $p$ value $>0.05$ ).

The heart rate before taking the patient to OT (t2) and before intubation ( $\mathrm{t} 3$ ) decreased by $0.8451 \%$ and $1.018 \%$ respectively in the Clonidine group. In the gabapentin group there was an increase of heart rate by $0.441 \%$ and $0.410 \%$ respectively before taking the patient to OT ( $\mathrm{t} 2$ ) and before intubation ( $\mathrm{t} 3$ ).But in both the groups the change of heart rate from baseline was not statistically significant in the prelaryngoscopic period. Also, among the two groups there was no significant difference of heart rate before taking the patient to OT ( $\mathrm{t} 2$ ) and before intubation ( $\mathrm{t} 3$ ).

The systolic blood pressure decreased by $0.76 \%$ before taking the patient to OT(t2) and $0.92 \%$ before intubation( $\mathrm{t} 3$ ) in the Gabapentin group. Similarly, in the Clonidine group also there was a fall of systolic blood pressure by $1.07 \%$ and $0.25 \%$ before taking the patient to OT (t2) and before intubation ( $\mathrm{t} 3$ ). However, no significant difference was present from the baseline values in both the groups. Also, among the two groups the systolic blood pressure differed insignificantly before taking the patient to OT and before intubation.

The Gabapentin group shows a statistically insignificant increase in diastolic blood pressure by $1.85 \%$ and $1.88 \%$ before taking the patient to OT ( $\mathrm{t} 2)$ and before intubation $(\mathrm{t} 3)$ respectively. In the Clonidine group, however initially there was a decrease of DBP by $0.49 \%$ followed by an increase of $2.296 \%$ respectively before taking the patient to OT (t2) and before intubation ( $\mathrm{t} 3$ ). However, these differences were not significant statistically. Among the two groups also in these time period the DBP does not differ significantly.

The mean arterial pressure in the Gabapentin group was more before taking the patient to OT (t2) and before intubation ( $\mathrm{t} 2$ ) by $0.68 \%$ and $0.62 \%$, but these changes from baseline MAP was minimal and was not statistically significant. In the Clonidine group the MAP decreased by $0.75 \%$ before taking the patient to OT $(\mathrm{t} 2)$ and increased by $1.15 \%$ before intubation ( $\mathrm{t} 3$ ). These changes were not statistically significant. Also, there were no significant difference of MAP among the two groups before taking the patient to OT ( $\mathrm{t} 2$ ) and before intubation ( $\mathrm{t} 3$ ).

The pulse pressure product also was near baseline in both the groups and there was no significant difference between the PPP among the two groups before taking the patient to OT ( $\mathrm{t} 2)$ and before intubation ( $\mathrm{t} 3$ ). From the above discussion it can be deduced that all the hemodynamic variables were similar to the baseline values before taking the patient to OT (t2) and before intubation (t2). Also, when compared among the two groups there were no significant difference. ( $p$ value $>0.05$ ).

Sarita Sharma et al conducted a comparative study where 120 patients were randomly allocated into four groups of 30 patients each: patients received oral $800 \mathrm{mg}$ of gabapentin (Group A), $300 \mu \mathrm{g}$ of clonidine (Group B), $400 \mathrm{mg}$ of gabapentin and $150 \mu \mathrm{g}$ of clonidine (Group C) and placebo (Group D); 60 minutes (min.) prior to induction of anaesthesia. Heart rate (HR), systolic blood pressure (SBP), diastolic blood pressure (DBP) and mean arterial blood pressure (MAP) were measured before induction, intubation and at 0,1,3,5 and 10 minutes after intubation. In their study they found that there was no statistically significant difference in HR, SBP, DBP and MAP amongst the four groups before intubation.

Geeta Bhandari et al ${ }^{15}$ conducted a study on effect of gabapentin at a dose of $900 \mathrm{mg}$ on pressor response to laryngoscopy and tracheal intubation when compared to placebo. They found that $0 \mathrm{~min}$ after intubation the mean diastolic blood pressure and heart rate were significantly less in the gabapentin group than the placebo group whereas there was no statistically significant difference in systolic blood pressure of both the group at o min after intubation was present. This study is also similar to our study except for the change in systolic blood pressure which was significantly lower in the Gabapentin group according to our study. Suresh K. Singhal et al who conducted a study to compare the effects of gabapentin $900 \mathrm{mg}$ and Clonidine $200 \mathrm{mcg}$ given $90 \mathrm{~min}$ prior to induction of anaesthesia also observed Side-effects pertaining to Clonidine and Gabapentin pre- and postoperatively. $68 \%$ of the patients in the Clonidine group complained of dry mouth pre-operative as well as postoperatively and bradycardia was observed in $2-4 \%$ cases, which did not warrant any treatment. Similarly, in the Gabapentin group there were minor complaints of headache, drowsiness and dizziness.

\section{Incidence of Side-Effects}

The incidence of side effects were reported in both the study groups. In the Clonidine group $10.67 \%$ of patients showed bradycardia whereas $9.33 \%$ patients complained of dryness of mouth in pre-induction period. In the Gabapentin group post-operative drowsiness was reported in $16 \%$ of patients

\section{CONCLUSIONS}

- Gabapentin $900 \mathrm{mg}$ attenuates the pressor response due to laryngoscopy and intubation better than Clonidine $200 \mathrm{mcg}$; however the attenuation of heart rate in both groups is similar.

- When Gabapentin is given in a dose of $900 \mathrm{mg}$ two hours before surgery, side effects like post-operative drowsiness can be seen.

- When Clonidine is given in a dose of 200 microgram, side effects like dryness of mouth and bradycardia can be seen.

- When compared to Clonidine, Ramsay sedation score is more in Gabapentin group.

\section{REFERENCES}

[1] Forbes AM, Dally FG. Acute hypertension during induction of anaesthesia and endotracheal intubation in normotensive man. Br J Anasth 1970;42(7):618-24. 
[2] Derbyshire DR, Smith G. Sympathoadrenal responses to anaesthesia and surgery. $\mathrm{Br} \mathrm{J}$ Anaesth 1984;56(7):725-39.

[3] Shribman AJ, Smith G, Achola KJ. Cardiovascular and catecholamine responses to laryngoscopy with or without tracheal intubation. $\mathrm{Br} \mathrm{J}$ Anaesth 1987;59(3):295-9.

[4] Derbyshire DR, Chmielewski A, Fell D, et al. Plasma catecholamine responses to tracheal intubation. $\mathrm{Br} \mathrm{J}$ Anaesth 1983;55(9):855-60.

[5] Russel WJ, Morris RG, Frewin DB, et al. Changes in plasma catecholamines concentrations during endotracheal intubation. Br J Anaesth 1981;53(8):8379.

[6] Kong VK, Irwin MG. Gabapentin: a multimodal perioperative drug? Br J Anaesth 2007;99(6):775-86.

[7] Stoelting R, Hillier S. Pharmacology \& physiology in anesthetic practice. $4^{\text {th }}$ edn. Philadelphia: Lippincott Williams \& Wilkins 2006.

[8] Raval DL, Mehta MK. Oral clonidine pre medication for attenuation of haemodynamic response to laryngoscopy and intubation. Indian J Anaesth 2002;46(2):124-9.

[9] Bafna U, Goyal VK, Garg A. A comparison of different doses of gabapentin to attenuate the haemodynamic response to laryngoscopy and tracheal intubation in normotensive patients. J Anaesthesiol Clin Pharmacol 2011;27(1):43-6.
[10] Sharma S, Angral R, Jamwal A, et al. Comparative evaluation of gabapentin, clonidine and combination of both the drugs to attenuate the pressor response to direct laryngoscopy and intubation. The Internet Journal of Anesthesiology 2012;30(4):1-6.

[11] Mamatha HK, George BA. Comparative clinical study of oral clonidine versus intravenous clonidine for attenuation of haemodynamic response to endotracheal intubation. IOSR Journal of Dental and Medical Sciences 2013;9(3):01-06.

[12] Soltanzadeh M, Soltani F, Mohtadi A, et al. Effects of preoperative oral gabapentin in reduction of intraocular pressure and cardiovascular changes following laryngoscopy and tracheal intubation. Life Science Journal 2012;9(3):908-11.

[13] Vyankatesh JS, Ramesh VD, Jamadar NP, et al. Attenuation of cardiovascular responses to laryngoscopy and endotracheal intubation: comparative evaluation of clonidine and lignocaine. Indian Journal of Basic \& Applied Medical Research 2012;1(4):313-23.

[14] Singhal SK, Kaur K, Arora P. Oral clonidine versus gabapentin as premedicant for obtunding hemodynamic response to laryngoscopy and tracheal intubation. Saudi Journal of Anesthesia 2014;8(2):1717.

[15] Bhandari G, Shahi KS. Effect of gabapentin on pressor response to laryngoscopy and tracheal intubation: a double blind randomized placebo controlled study. People's Journal of Scientific Research 2013;6(1):1-6. 